\title{
Elaboration of Innovative Medical Devices by Dispersing Fatty Acid Eutectic Blend on Gauzes Using Supercritical Particle Generation
}

\section{Processes}

Joana M. Silva ${ }^{1,2}$, Salah Akkache ${ }^{3}$, Ana C. Araújo ${ }^{1,2}$, Yasmine Masmoudi ${ }^{3}$, Rui L. Reis $^{1,2,4}$, Elisabeth Badens ${ }^{3}$, Ana Rita C. Duarte ${ }^{1,2 \# *}$

1 3B's Research Group- Biomaterials, Biodegradable and Biomimetic, University of Minho, Headquarters of the European Institute of Excellence on Tissue Engineering and Regenerative Medicine, Avepark 4805-017 Barco, Guimarães, Portugal

${ }^{2}$ ICVS/3B's PT Government Associated Laboratory, Braga/Guimarães, Portugal

${ }^{3}$ Aix Marseille Univ, CNRS, Centrale Marseille, M2P2, Marseille, France

${ }^{4}$ The Discoveries Centre for Regenerative and Precision Medicine, Headquarters at University of Minho, Avepark 4805-017 Barco, Guimarães, Portugal

Corresponding author: ard08968@fct.unl.pt

\# Current Address: LAQV-REQUIMTE, Chemistry Department, Faculty of Science and Technology, Nova University of Lisbon, 2829-516 Caparica, Portugal 


\begin{abstract}
Loading medical devices with antibacterial agents is an interesting solution to limit bacterial infections during wound treatment. Herein, an innovative system with thermosensitive properties was produced, loading a commercially available gauze with a fatty acid eutectic blend based on lauric acid (LA) and myristic acid (MA). Such eutectic blend presents a melting point near physiological temperature, which together with its anti-bacterial properties make their use an alternative in biomedical applications. At room temperature, the properties and efficacy of eutectic blend loaded on gauzes are preserved, whereas at physiological temperature the eutectic blend undergoes a phase change that facilitates its diffusion from the gauze. The loading of the eutectic blend on gauzes was performed using two different supercritical fluid technologies, namely, particle from gas saturated solutions (PGSS) and a derived version of rapid expansion of supercritical solution (D-RESS). PGSS led to a heterogeneous dispersion of the eutectic blend in the gauze, whereas a homogeneous dispersion along the surface of the gauzes was obtained through the D-RESS process. Additionally, with D-RESS no phase separation of the eutectic blend occurs and the cytotoxicity was greatly improved when compared with PGSS without compromising the antibacterial properties. Hence, the present study highlights the potential use of the flexible D-RESS process to load eutectic blends with antibacterial properties on medical devices.
\end{abstract}

Keywords: Fatty Acids, Eutectic mixture, D-RESS, PGSS, Antibacterial, Thermosensitive devices. 


\section{INTRODUCTION}

Fatty acids are naturally occurring compounds commonly extracted from vegetal and animal fats and oils using conventional separation processes or produced by specific routes from triacylglycerols.[1,2] Chemically, fatty acids are carboxylic acids with long, unbranched aliphatic chains, that could be either saturated or unsaturated. These amphiphilic molecules present a non-polar aliphatic chain and a polar acid functional group.[3-6] The remarkable properties of fatty acids led to their widespread use in agriculture, food industries, cosmetic, nutraceutical, pharmaceutical and biomedical applications. Among their biomedical applications, the antibacterial action of fatty acids and monoglycerides has been extensively studied and reported over the past several years.[7-9] Fatty acids are key elements in the self-disinfection of human skin, being secreted from sebaceous gland and subsequently release through hydrolysis.[10] In this context, eutectic blends based on fatty acids with antibacterial ability present a tremendous interest, since it allows the mixture of two or more fatty acids, which at a certain molar ratio presents a melting temperature far below than either of its individual components due to the establishment of intermolecular hydrogen bonds and aoccasionally van der Waals interactions.[11-17] Generally, the preparation of an eutectic system is straightforward and simple, being achieved by a physical mixing of compounds using temperature and constant stirring to accelerate the process.[17-21] Over the past years, series of binary and multiple fatty acid eutectics such as ternary, quaternary and quinary eutectics were successfully prepared (Table 1), as the number of compounds and their arrangements are virtually unlimited which allow to customized the blends for specific applications.[13, 15, 20, 22]

The properties of eutectic blends turns them attractive for biomedical and biotechnological fields including their use as therapeutic delivery carriers of active pharmaceutical ingredients (API's) is well-reported since 1998 due to their strong ability to increase the solubility and/or permeability of a wide panel of API's in several folds, when compared with their solubility in water.[17, 23-30] Till now, the antimicrobial, antipruritic, anti-inflammatory, antitussive and analgesic properties of different eutectic blends have been reported in the literature. refs Herein, an eutectic blend based on lauric acid (LA) and myristic acid (MA) were selected in view of its melting temperature near physiologic temperature and also due to the higher antibacterial properties of the counterparts when compared with other fatty acids.[19, 31] Even though, the production and characterization of such eutectic blends (i.e., LA:MA) have been already reported 
[31] to the best of our knowledge this is the first time that their loading on medical devices and also their antibacterial properties are being evaluated.

Table 1: Distribution of melting peak temperatures of different fatty acids eutectic blends

\begin{tabular}{c|c|c}
\hline Melting Temperature $\left({ }^{\mathbf{0}} \mathbf{C}\right)$ & Eutectic Mixture & Ref. \\
\hline $\mathbf{1 5 - 2 0}$ & CA:LA:MA; CA:LA:PA:SA & {$[19,32,33]$} \\
& CA:LA:MA:SA; CA:LA:MA:PA & \\
\hline $\mathbf{2 0 - 2 5}$ & CA:LA; CA:PA:SA; CA:MA:SA; & {$[19,31-33]$} \\
& CA:MA:PA; CA:LA:SA; & \\
\hline $\mathbf{2 5 - 3 0}$ & CA:LA:PA; CA:MA:PA:SA & \\
\hline $\mathbf{3 0 - 3 5}$ & CA:MA; CA:PA; LA:MA:PA:SA & {$[19,31,32,34$,} \\
& CA:SA; LA:MA:SA; LA:MA:PA; & {$[19,31,32]$} \\
\hline $\mathbf{3 5 - 4 0}$ & LA:MA:PA:SA & {$[19,31,32]$} \\
\hline $\mathbf{4 0 - 4 5}$ & LA:MA; LA:PA; LA:PA:SA & {$[19,32,36]$} \\
\hline (*) Capric acid (CA); Lauric Acid (LA); Stearic Acid (SA), Myristic Acid (MA); Palmitic Acid(PA)
\end{tabular}

In this work, the loading of the gauzes was performed using supercritical carbon dioxide $\left(\mathrm{scCO}_{2}\right)$ based processes, namely particle from gas saturated solution (PGSS) and a derived version of rapid expansion of a supercritical solution (RESS). These processes have been widely applied for the micronization of active pharmaceutical ingredients (APIs) and/or for the elaboration of composite (APIs/excipient) formulations.[37, 38] In PGSS process, the $\mathrm{scCO}_{2}$ is used as a dispersion agent, which implies the solubilization of $\mathrm{scCO}_{2}$ in the solute, namely a polymer [39, 40] or a solid lipid [41, 42]. Alternatively, the RESS process has been reported as a suitable approach to process compounds which are soluble in $\mathrm{scCO}_{2}$.[43] In this study, as mutual solubility between fatty acids and $\mathrm{CO}_{2}$ depends on the experimental conditions, PGSS and D-RESS were investigated in order to evaluate the technical feasibility of particle generation to load gauzes with fatty acids eutectic blend in a single step process. Herein, the aim of the present study is to provide clues on the development of a straightforward method to load fatty acids eutectic blend in gauzes, which enhance the diffusion of fatty acids, while preserving their antibacterial properties. The comprehensive strategy includes the preparation and characterization of the eutectic blend followed by the loading on medical devices and the evaluation of their biological properties. 


\section{MATERIALS AND METHODS}

\section{Preparation of the eutectic mixture}

During the preparation of the eutectic mixture, lauric acid (LA; Ref. W261408SAMPLE-K, Sigma Aldrich) and myristic acid (MA; ref.70082, Sigma Aldrich) were used as raw materials. The systems were prepared by gently mixing the two components at a molar ratio of $1: 1$, according to a previous work.[31] The mixture was heated to $70^{\circ} \mathrm{C}$, under constant stirring, until a clear liquid solution was formed. Afterwards the mixture was slowly cooled down to room temperature (RT).

\section{Polarized Optical Microscopy (POM)}

Optical characterization of LA:MA eutectic blend was carried out at RT by POM using and Olympus BH2 transmission microscope (Olympus, UK) coupled with a Leica digital camera DFC 280 (Leica, UK). The eutectic mixture was heated and a drop of LA:MA blend was deposited on a microscopic glass slide.

\section{Viscosity measurements}

The viscosity of the eutectic blend was measured using a Kinexus Prot Rheometer (Kinuxus Prot, MaL 1097376, Malvern) fitted with parallel plate geometry with $20 \mathrm{~mm}$ of diameter (PU20 SR1740 SS) and $1 \mathrm{~mm}$ of gap. The viscosity of LA:MA eutectic blend was assessed under controlled stress conditions and a shear rate of $10 \mathrm{~s}^{-1}$. A temperature scan was performed from $50^{\circ} \mathrm{C}$ to $15^{\circ} \mathrm{C}$ at $2^{\circ} \mathrm{C} \mathrm{min}^{-1}$.

\section{Differential Scanning Calorimetry (DSC)}

The DSC experiments were performed in a TA instrument DSC Q100 model (Thermal analysis \& analysers, USA), using the different formulations in a TA aluminium pan. The temperature ramp included a heating step from $0 \mathrm{C}$ to $80^{\circ} \mathrm{C}$, followed by an isothermal step of 2 minutes prior to cooling down the system to $20^{\circ} \mathrm{C}$. All measurements were performed under nitrogen atmosphere (purge gas flux of ca. $50 \mathrm{~mL} \mathrm{~min}^{-1}$ ) and at a heating rate of $5^{\circ} \mathrm{C} \mathrm{min}^{-1}$.

\section{Assessment of antibacterial properties of the eutectic blend}

The antibacterial activity of eutectic blends was determined using Staphylococcus aureus (S. aureus, ATCC 25923) and Pseudomonas aeruginosa (P.aeruginosa, ATCC 27853), according to Clinical and Laboratory Standards Institute (CLSI) guidelines. The 
antibacterial activity was initially screen out using the disc diffusion approach. Gentamicin sulphate (ref. G1914, Sigma Aldrich) at $50 \mathrm{mg} / \mathrm{mL}$ and sterile water were used as positive and negative control, respectively. Additionally, the effect of each fatty acid was also evaluated. The discs (CT0998B, Oxford) were prepared by incubating them in eutectic blend and controls. Prior to the disk diffusion assay, suspension cultures were prepared by the inoculation of single colonies in $5 \mathrm{~mL}$ of tryptic soy broth (TSB, ref CM0337B, Frilabo). The cultures were grown for $24 \mathrm{~h}$ at $37{ }^{\circ} \mathrm{C}$ in an orbital shaker at $120 \mathrm{rpm}$. Afterwards, bacteria cells were harvested and re-suspended in TSB and the absorbance at $640 \mathrm{~nm}$ was adjusted to a turbidity of $0.5 \mathrm{McF}$ arland scale, which provides an equivalent concentration of $1-2 \times 10^{8}$ colony forming units (CFUs) $/ \mathrm{mL}$. The inoculum was then distributed in Müller-Hinton agar (MHA, ref. CM0337B, Fisher Scientific) plates. Then the disks with the different formulations were placed on the inoculated agar. The plates were incubated during $18-24$ hours at $37^{\circ} \mathrm{C}$. After incubation, the diameter of the clear zone (inhibition halo diameter) was determined.

The minimal inhibitory concentrations (MICs) and minimal bactericidal concentrations (MBCs) were determined by microbroth dilution technique. Briefly, standard solutions of fatty acids in powder and in eutectic blend form were prepared under sterile conditions by first dissolving the weighed compounds in ethanol $96 \%$ (ref. E/0650DF/C17, Enzymatic) and serially diluted them in Müller-Hinton Broth medium (MHB, ref 70192-500g, Sigma Aldrich) up to $156 \mu \mathrm{g} / \mathrm{mL}$. Prior to use, the tubes were warmed up to $70^{\circ} \mathrm{C}$ and homogenized using an ultrasonic bath, according to previous reported protocols in the literature as fatty acids are highly insoluble.[44-46] Afterwards, the different formulations were dispensed into the wells (100 $\mu \mathrm{L} /$ well) being inoculated with $100 \mu \mathrm{L}$ of the bacterial suspension at $1-2 \times 10^{6} \mathrm{CFUs} / \mathrm{mL}$ in MHB. A, a solution of $10 \%$ ethanol in MHB, MHB bacteria-free and the pure fatty acids (i.e., LA and MA) were used as controls. The plates were incubated at $37^{\circ} \mathrm{C}$ during 24 hours under shaking and the bacterial growth was monitored. The MICs of each compound were considered to be the concentrations at which the no turbidity was observed. However, to confirm such results and to avoid underestimated values (i.e., the compound itself may cause turbidity), subcultures of each concentration were performed onto trypticase soy agar (TSA, Ref. 610052, Frilabo) during 24 hours. This assay allows to confirm the MICs values and also the determination of the MBCs of each compound. The MBCs were considered as the minimal concentration of each formulation required to kill S.aureus CFUs. Experiments were carried out in triplicate and repeated in three independent occasions. 
Assessment of cytotoxicity

$\operatorname{xxxxx}$

\section{Supercritical process for loading gauzes with an eutectic blend}

Gauze loading with fatty acids eutectic blend was carried out through the experimental set-up illustrated in Figure $1 . \mathrm{ScCO}_{2}$ is supplied through a feeding line composed by a high-pressure pump (LGP 50, Separex S.A. France). $\mathrm{ScCO}_{2}$ is introduced in a $500 \mathrm{~mL}$ autoclave (Top industrie S.A., France) with handling pressures up to $300 \mathrm{bar}$, temperatures up to $150^{\circ} \mathrm{C}$, and a hemispherical bottom, which facilitates the viscous solution flow in the PGSS configuration. The autoclave is also equipped with an anchor shape agitator and a bottom valve. The control over temperature is performed using a double jacket connected to a thermostatic bath. Downstream the autoclave, a double valve system (ball valves) is used to control the solution expansion occurring through a $1.8 \mathrm{~mm}$ inner diameter nozzle into a recovery vessel in which gauzes $\left(1 \mathrm{~cm}^{2}\right.$ surface area) are deposited. The dispersion line is heated to the working temperature, compensating the endothermic effect during the expansion phase. The recovery vessel is in plexiglass, allowing the visualization of the jet dispersion. During the experiment, the autoclave is first filled with predetermined amounts of LA:MA (1:1 molar ratio) eutectic blend, fixed according to the selected process configuration (PGSS or D-RESS). The difference in process configuration is merely dictated by the amount of fatty acids loaded in the vessel, being the experimental procedure equivalent in both cases. The autoclave is set up to $40^{\circ} \mathrm{C}$ and loaded with pre-heated $\mathrm{CO}_{2}$ using the high-pressure pump in a pressure regulation mode set to 100 bar. After an equilibrium of two hours under agitation, the loading was carried out. For that purpose, the bottom valve is opened and the equilibrium was set for $1 \mathrm{~min}$, while the double valve of the expansion system was kept closed. The valve $\mathrm{V}_{1}$ is opened where the valve V2 is kept closed. Since, a weak expansion occurs in the system, an equilibrium duration of 15 seconds was set to reach the working pressure (pressure regulation mode of the high-pressure pump) and temperature. The valve $\mathrm{V}_{1}$ is then closed, whereas the $\mathrm{V}_{2}$ is opened. The solution contained within the double valve system is expanded through a $1.8 \mathrm{~mm}$ inner diameter nozzle leading to fatty acid projection on the gauzes within the recovery vessel. 


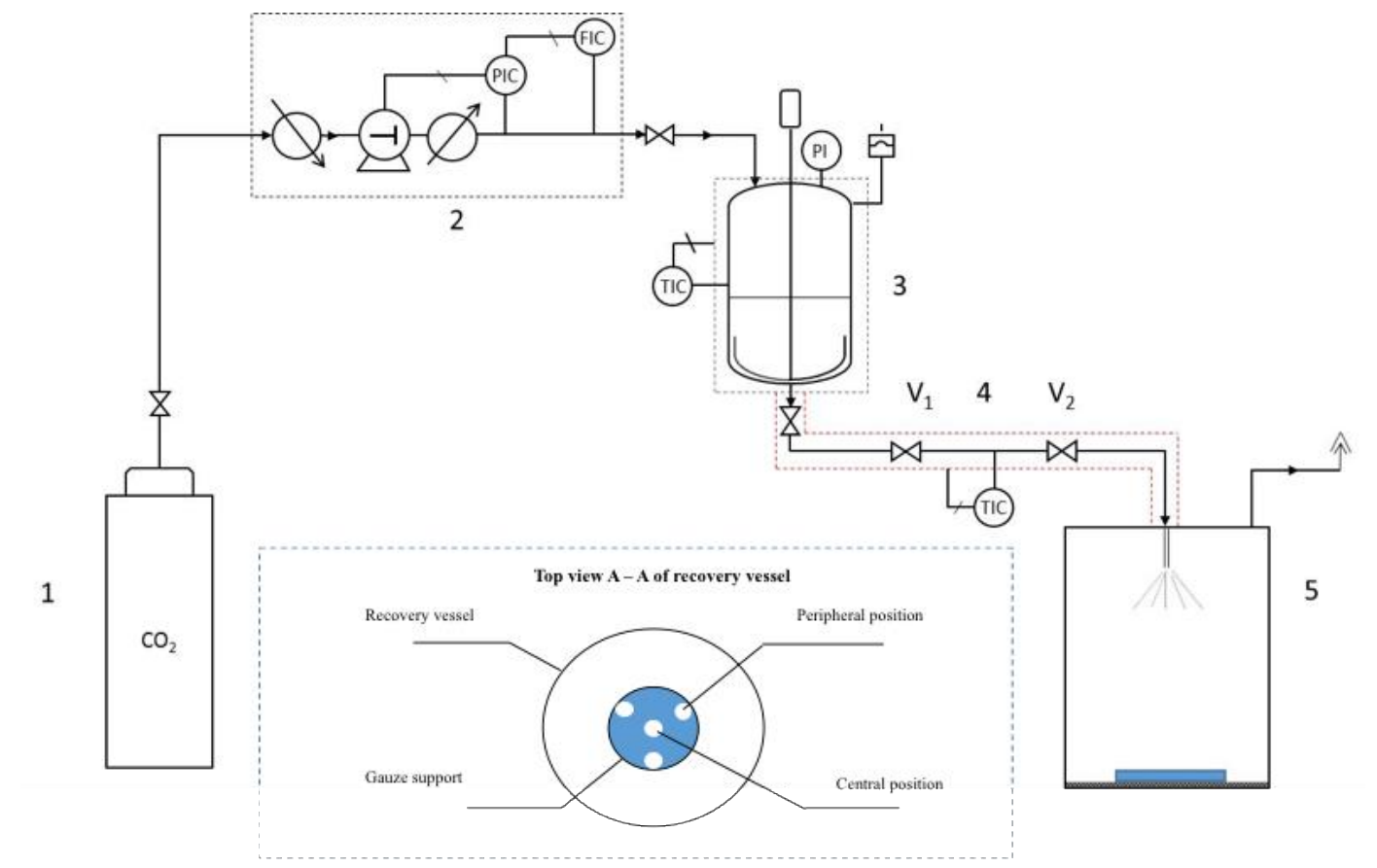

Figure 1: Schematic flow diagram of high-pressure set-up used for gauze loading (1) $\mathrm{CO}_{2}$ cylinder, (2) $\mathrm{scCO}_{2}$ feeding line, (3) autoclave, (4) double valve system, (5) recovery vessel.

\section{Fluid phase equilibria visualization}

A variable volume high-pressure cell (Top Industrie S.A., France) equipped with a manual internal movable piston and a sapphire window (15 $\mathrm{mm}$ diameter) was used to study the fluid phase equilibria of ternary (LA:MA)- $\mathrm{CO}_{2}$ system. The experimental setup was previously reported by Crampon et al.[47]. Briefly, the experimental procedure consists in adding known amounts of eutectic blend and $\mathrm{CO}_{2}$ in the cell. After heating the system to $40^{\circ} \mathrm{C}$, the pressure is progressively increased (i.e., 1 bar increment) by moving the manual piston in isothermal conditions under magnetic stirring. The sapphire window allows a direct visualisation of the phases (i.e., single and two phases) in the high-pressure cell.

\section{Staining with oil red}

The oil red (ref. 715113, Sigma Aldrich) was used to stain the gauzes with and without eutectic blends of fatty acids. The oil red powder was dissolved in isopropanol (ref. 20842.330, VWR) to yield a concentration of $5 \mathrm{mg} \mathrm{mL}^{-1}$ (stock solution).[48, 49] The gauzes were immersed in a working solution of oil red/water (3:2) during 2 hours. After the washing step, the samples were observed in a stereomicroscope (Zeiss, Germany) with a colour camera (Nikon G12). 


\section{Determination of fatty acid loading in gauzes}

The determination of the fatty acid loading was performed by a derivatization of fatty acids to fatty acid methyl esters (FAMES), according to previous protocols reported in literature.[50, 51] Briefly, fatty acids eutectic blend was prepared at $16 \mathrm{mg} \mathrm{mL}^{-1}$ and gauzes $\left(1 \mathrm{~cm}^{2}\right)$ were incubated overnight with $2 \mathrm{~mL}$ of chloroform (Ref. C/4960/17, Enzymatic) under constant shaking. As standards, a physical mixture of LA and MA at molar ratio of 1:1 was prepared at different concentrations. Additionally, stearic acid (Ref. 175366, Sigma Aldrich) was used as internal standard at a concentration of $500 \mu \mathrm{g}$ $\mathrm{mL}^{-1}$ in chloroform. A methylation solution was also prepared by a dropwise addition of sulfuric acid (Ref.524541, Laborspirit) to methanol (Ref. M/4000/17, Enzymatic) at a ratio of 9:1 (v/v). For the derivatization, $50 \mu \mathrm{L}$ of sample, $1 \mathrm{~mL}$ of methylation solution and $100 \mu \mathrm{L}$ of internal standard were added to a digestion tube. The different tubes were tightly closed and the reaction was allowed to proceed at $100^{\circ} \mathrm{C}$. After 2 hours, the tubes were cooled down and $2 \mathrm{~mL}$ of hexane (ref. 34859, VWR) was added. The upper phase (hexane phase) was then transferred to a glass vial and sodium sulphate anhydrous (ref.238597, Sigma Aldrich) was added. After this stage, the sample can be transferred to a vial and analysed in Gas chromatography-mass spectrometry (GC-MS, Scion 436501, Bruker, USA) in the following conditions: column (SLB-IL100, Sigma Aldrich); temperature of column $50^{\circ} \mathrm{C}$ during 5 min followed by a heating ramp until $230^{\circ} \mathrm{C}$ at $3^{\circ} \mathrm{C}$ $\min ^{-1}$; a gas drag $\mathrm{He} 1 \mathrm{~mL} \mathrm{~min}^{-1}$; injector at $250^{\circ} \mathrm{C}$, a split 1:20, an injection volume of 1 $\mu \mathrm{l}$; a transfer line at $230^{\circ} \mathrm{C}$ and a source of ionization at $250^{\circ} \mathrm{C}$. The standard curve was created and the amount of each fatty acid was read off the standard curve.

\section{Morphology of gauzes}

The morphology of the gauzes with and without the eutectic blend was observed by scanning electronic microscopy (SEM JSM-6010LV, JEOL, Japan) operating at an accelerating voltage of $15 \mathrm{kV}$. All the samples were sputtered coated with a conductive platinum layer, using a sputter coater EM ACE600 (Leica, Austria).

\section{In vitro biological performance of gauzes with $\mathrm{L929}$ cells}

To evaluate the biological performance of gauzes loaded with fatty acids, cell culture studies were performed with L929, a mouse fibroblast of connective tissue cell line (European Collection of Cell Cultures (ECCC), UK). Cells were cultured in Dulbecco's modified Eagle's medium (DMEM, Sigma, USA), supplemented by $10 \%$ 
heat-inactivated fetal bovine serum (FBS, Biochrome AG, Germany) and $1 \%$ antibioticantimicotic (Gibco, USA). The cytotoxicity was studied by analysing the effect of the extracts of gauzes on the cell's metabolism, which is in accordance with ISO/EN 10993 guidelines. In addition, the gauzes with and without fatty acids were also placed in contact with cell monolayers. The morphological changes of cells after 24 hours in contact with extracts and gauzes was observed by optic microscopy (AxiovertA1, Zeiss, Germany). The cell viability was determined by CellTiter 96® Aqueous One Solution Cell Proliferation Assay. The amount of formazan product was measured by absorbance at a wavelength of $490 \mathrm{~nm}$ using a microplate spectrophotometer (Bio-TEK, USA).

\section{Assessment of the antibacterial properties of gauzes loaded with eutectic blends}

The antibacterial properties of gauzes loaded with eutectic blends was evaluated against S.aureus. Prior to the assay, both sides of gauzes were sterilized by UV during 20 minutes. For the assay, the different formulations were inoculated with a bacterial suspension of $1-2 \times 10^{5} \mathrm{CFU} / \mathrm{mL}$ in TSB. After inoculation, the content of each tube was incubated at $37^{\circ} \mathrm{C}$ under vigorous agitation during 24 hours. Following the incubation, serial dilutions $\left(1: 10 ; 1: 100 ; 1: 1000 ; 1: 10000 ; 1: 1 \times 10^{5}, 1: 1 \times 10^{6}, 1: 1 \times 10^{7} ; 1: 1 \times 10^{8}\right)$ were prepared and the inoculum of each tube was then plated in TSA. After 24 hours of incubation the number of CFUs in the culture plates were determined. To test the effectiveness of the gauzes loaded with eutectic blend, a non-treated gauze was used as control as well as the S.aureus in TSB. The morphology of the $S$. aureus in contact with gauze was also evaluated by SEM and compared with non-treated gauze without treatment and also with the positive control (i.e., bacteria in coverglass). Briefly, after 24 hours of incubation the culture medium was removed and the samples were fixed in $10 \%$ v/v of formalin (ref. 5701, Grupo Taper). After 30 minutes, formalin was removed and

the samples were washed in PBS before being dehydrated in series of ethanol. After drying, the samples were platinum sputtered and visualized by SEM.

\section{Statistical analysis}

The experiments were carried out in triplicate otherwise specified. The results were presented as the mean \pm standard deviation (SD). Statistical analysis was performed by Shapiro Wilk normality test using Graph Pad Prism 7. After this analysis, parametric tests (one-way Anova followed by Tukey test) were applied. 


\section{RESULTS AND DISCUSSION}

\section{Preparation and characterization of the eutectic blend}

In this work, LA and MA in their solid state were mixed at a molar ratio of 1:1, according to a previous work of Meng and co-workers.[31] Using a molar ratio of 1:1, a clear and transparent liquid (no insoluble particles were visible with the naked eye) was obtained at temperatures above physiological-like conditions, whereas upon slowly cooling down to RT a pasty-like solid with uniformly mixed fatty acids was obtained. The successful production of the eutectic blend was screen out using DSC and POM techniques (Figure 2). Using DSC technique, the thermal behaviour of the eutectic blend was studied and compared to the ones of the individual pure starting components. The obtained spectra are in accordance with the ones previously obtained in the literature. [19, 31, 52-55] In the DSC thermogram of the eutectic blend, a unique, sharp and well-defined peak appeared during the heating step, which indicates the establishment of intermolecular interactions between the pure compounds, namely through hydrogen bonding interactions. In addition, the melting point of the eutectic mixture is lower $(\approx$ $\left.37.25 \pm 0.50{ }^{\circ} \mathrm{C}\right)$ than the one of $\mathrm{LA}\left(\approx 46.18 \pm 0.14{ }^{\circ} \mathrm{C}\right)$ and $\mathrm{MA}\left(\approx 57.85 \pm 0.14{ }^{\circ} \mathrm{C}\right)$, confirming the successful formation of an eutectic mixture that features the same stability of the single components.[1, 19, 36, 56] Similar behaviour has been reported in the literature, being well established that eutectic blends of two or more kinds of individual fatty acids at specific molar ratio is an efficient approach to tune their phase change temperatures.[32, 53, 57] The results were further corroborated by POM analysis (inset micrographs of Figure 2A), where the results indicate the presence of crystal-like structures at temperatures below the melting point of the eutectic blend, whereas at higher temperatures the eutectic blend became liquid and a full black background was obtained. 


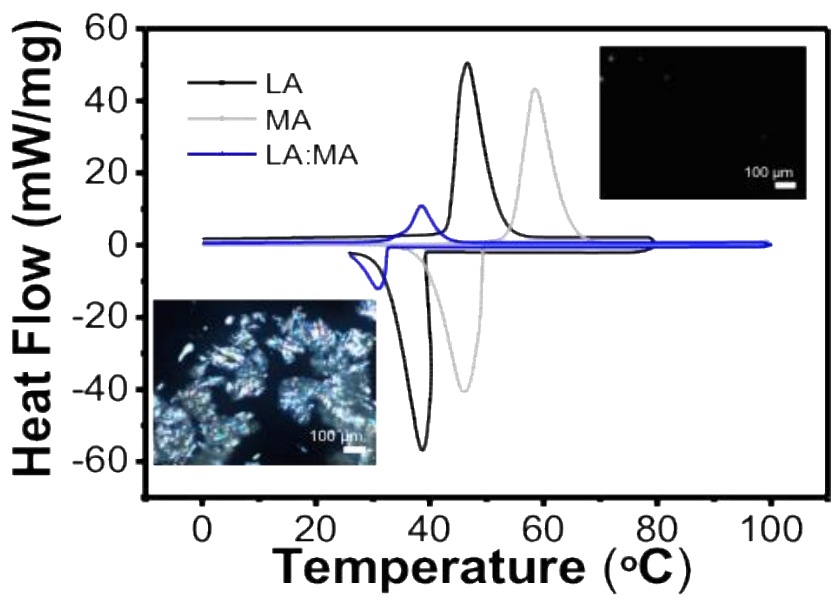

Figure 2. Thermograms obtained for LA, MA and LA:MA eutectic blend (1:1). The inset POM microphotographs were obtained below and above the melting temperature of LA:MA eutectic blend (1:1).

The characterization of the physical properties of the eutectic blend, such as viscosity, was also assessed (Figure 3). As expected, the results indicate a decrease in the viscosity as the temperature increases, particularly from $30^{\circ} \mathrm{C}$ to $50^{\circ} \mathrm{C}$. This behaviour can be explained by the lower melting point of the eutectic blend, which is close to the physiological temperature, corroborating the results obtained with the DSC thermograms. Thus, close to the melting temperature of the eutectic blend, the viscosity reaches values of nearly $0.004 \mathrm{~Pa} . \mathrm{s}$, whereas at $30^{\circ} \mathrm{C}$ the viscosity reaches almost $73 \mathrm{~Pa} . \mathrm{s}$. The decrease of viscosity as the temperature increase is in accordance with the Arrhenius equation.[8, $10,11]$ The viscosity of the fatty acid eutectic blends is an important parameter that dictates the diffusion of the eutectic blend from the gauzes once the eutectic melting temperature is achieved and when applied to the patient. The results indicate a strong decrease in the viscosity of the fatty acids, and, thus an enhanced rate of transport.[58, 59] 


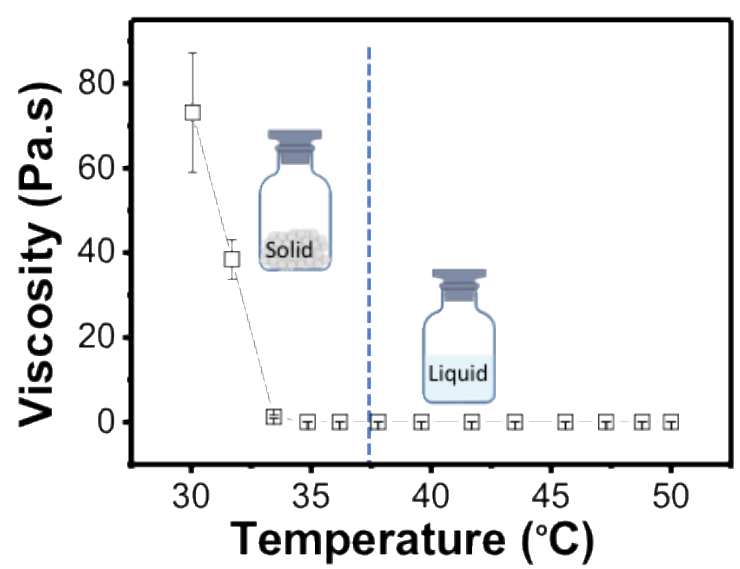

Figure 3: Variation of viscosities of LA:MA eutectic blend (1:1) as a function of temperature.

\section{Antibacterial properties of the eutectic blend}

The interaction of LA, MA, eutectic blend and controls (i.e., gentamicin sulphate sterile water) with S.aureus (gram positive) and P.aeruginosa (gram negative) was initially evaluated through the disc diffusion approach, which is commonly used in microbiology to test the diffusible antimicrobial activity of novel formulations.[61, 62] (Figure 4). These strains were selected as they are usually present in nosocomial infections such as skin infections. [60] The results indicate that in contact with S.aureus a clear inhibition zone (i.e., a clear halo) was observed around all the disks, with exception of the ones with distilled water (i.e., the negative controls). An opposite behavior was observed when the disks were in contact with P.Aeruginosa, as no inhibition in bacteria growth around the disks was observed. Thereby, the results indicate a potential antibacterial activity of pure fatty acids and eutectic blends against $S$. aureus, which is a gram-positive bacterium. The resistance of P.aeruginosa to pure fatty acids and, consequently, to the eutectic blend is consistent with the literature and it can be explained by structural differences on the surface of bacteria.[3, 45] Several studies reported that fatty acids are not biologically active towards gram negative strains due to the presence of lipopolysaccharides on the cell wall, which prevents the fatty acids from reaching cell membrane and entering in the cells. [3, 45, 63] On other hand, the cell wall of gram positive may absorb and transport fatty acids into the inner membrane. [3, 45] 


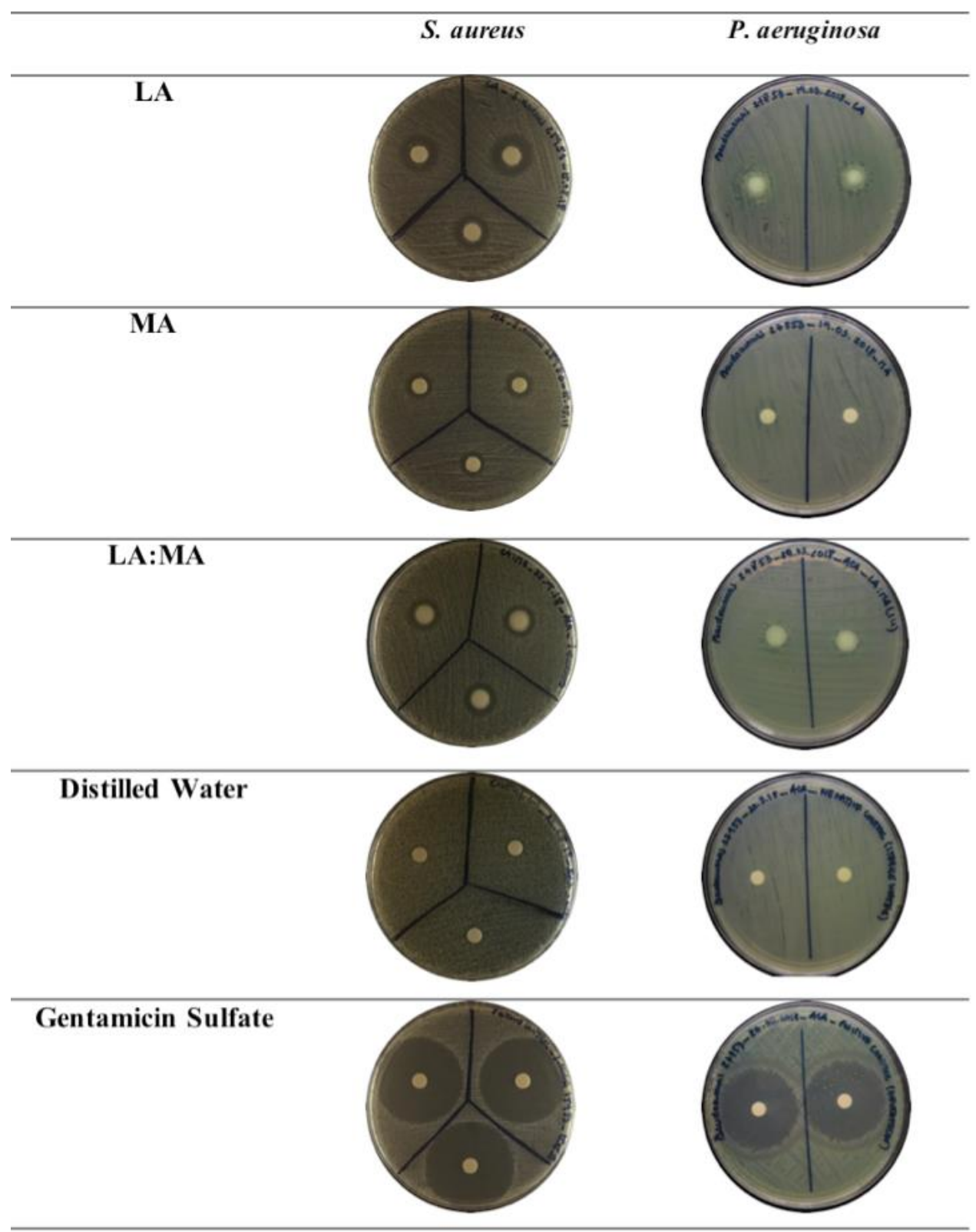

Figure 4. Antibacterial activity of the individual fatty acids, eutectic blend and controls: Agar diffusion assays with two strains, S.aureus and P.aeruginosa.

To easily compare the data in the different formulations against both strains, the inhibition halo diameter of both strains was also determined (Table 2). As expected, the only compound able to form a clear inhibition zone in the gram-negative strain was the gentamicin sulfate, the positive control. For the S.aureus strain, the results of the individual fatty acids indicate that the inhibition zone was higher for LA than MA. In the eutectic mixture the inhibition halo diameter is similar to the one of MA, indicating that using both components at equimolar molar ratio, LA is not able to potentiate the antibacterial properties of the overall mixture. 
Table 2: Antibacterial activity of the different formulations against S.aureus and P.aeruginosa through the disc diffusion approach.

Inhibition halo diameter ( $\mathrm{mm})$

\begin{tabular}{l|c|c}
\hline & S.aureus & P.aeruginosa \\
\hline LA & $14.33 \pm 0.55$ & NI \\
\hline MA & $11.11 \pm 0.00$ & NI \\
\hline LA:MA & $12.00 \pm 0.00$ & NI \\
\hline Distilled Water & $0.00 \pm 0.00$ & NI \\
\hline Gentamicin sulfate & $37.11 \pm 0.24$ & $34.00 \pm 0.82$ \\
\hline
\end{tabular}

After the initial screening with the disc diffusion approach, the susceptibility of S.aureus against the pure components and eutectic blend was quantitatively determined by MICs and MBCs (Table 3). The MICs indicate the formulation that requires lower concentration to inhibit the bacteria growth, whereas the MBCs indicate the minimum concentration able to kill the bacteria inoculum.[10] The results indicate that the lowest MICs and MBCs were obtained for LA. The strong antibacterial properties of LA against gram positive bacteria is in agreement with the trend shown in several studies.[3, 7,10 , 45] The antibacterial activity of fatty acids is dependent on several factors including chain size, hydrophobicity, number and position double bonds and functional groups.[44, 63, 64] In saturated fatty acids, one of the most important features is a correct balance between hydrophobicity and hydrophilicity, as higher hydrophobicity may prevent fatty acids to reach a concentration sufficient to interact with lipids and proteins on the bacteria cell surface.[3] Additionally, it is assumed that lower chain lengths saturated fatty acids are more effective against microorganisms.[63, 64]

Table 3. Minimal inhibitory concentrations (MICs) and minimal bactericidal concentration (MBCs) of pure components and eutectic blend.

\begin{tabular}{c|c|c}
\hline & $\begin{array}{c}\text { MIC } \\
(\mu \mathrm{g} / \mathrm{mL})\end{array}$ & $\begin{array}{c}\text { MBC } \\
(\mu \mathrm{g} / \mathrm{mL})\end{array}$ \\
\hline LA & 312 & 625 \\
\hline MA & 625 & 1250 \\
\hline LA:MA & 625 & 1250 \\
\hline
\end{tabular}

These results also indicate that besides no major differences in susceptibilities were observed between MA and the eutectic blend, the hydrogen interactions established 
between both fatty acids do not compromise the antibacterial capacity of the counterparts. xxxxxxx Additionally, it should be noted that values obtained for MICs and MBCs in the individual counterparts are in agreement with the ones reported in literature. [44, 45] Furthermore, it should be point out that the determination of antibacterial against fatty acids is trickily due to the turbidity of lipid-based solutions. To solve such drawback, $10 \%$ ethanol was added to the medium and such percentage did not show any effect on MICs and MBCs determination. The data obtained highlights the potential of the eutectic blend against S.aureus, which is highly common in nosocomial and community-acquired infections.

\section{Gauzes loaded with an eutectic blend of fatty acids by two different} supercritical fluid approaches

Upon evaluating the favourable antibacterial properties of the eutectic blend, it is worthwhile to test the technical feasibility of gauze loading through PGSS and D-RESS processes. Among the promising features of such supercritical fluid approaches are the facile pulverization of melted solutions, the possibility to avoid organic solvents, the low consumption of $\mathrm{CO}_{2}$, and lastly, the high yields of precipitation when compared with former techniques.[65, 66] Even though the solubilities of LA and MA in $\mathrm{CO}_{2}$ have been already studied in the literature in experimental conditions close to the ones used in this study, as far as we know, the solubility of LA:MA eutectic blends in $\mathrm{scCO}_{2}$ has not been yet reported.[67, 68] The results from vapor-liquid equilibrium indicate that the LA:MA eutectic blend is highly soluble in supercritical $\mathrm{scCO}_{2}$ and depending on the composition of the ternary system (LA:MA:CO 2 ), it is possible to use both configurations, PGSS or D-RESS. In a first approximation, using the correlation published by Maheshwari and coworkers[69], the solubilities of each pure fatty acid (LA and MA) at 100 bar and $40^{\circ} \mathrm{C}$ were estimated to $54.8 \mathrm{~g} \mathrm{~kg}^{-1} \mathrm{CO}_{2}$ and $37.7 \mathrm{~g} \mathrm{~kg}^{-1} \mathrm{CO}_{2}$, respectively. The fatty acid contents and experimental conditions of both configurations are given in Table 4. The LA:MA: $\mathrm{CO}_{2}$ ternary systems were observed in the high-pressure view cell to verify the existence of a single or two phases (Figure 5). 
Table 4: Experimental conditions PGSS and D-RESS configurations

\begin{tabular}{c|c|c|c}
\hline $\begin{array}{c}\text { LA content / LA } \\
\text { saturation }\end{array}$ & $\begin{array}{c}\text { MA content / MA } \\
\text { saturation }\end{array}$ & $\begin{array}{c}\text { Observation in } \\
\text { view cell }\end{array}$ & $\begin{array}{c}\text { Process } \\
\text { configuration }\end{array}$ \\
\hline 1.25 & 1.61 & $\begin{array}{c}\text { Two phases } \\
\text { (liquid - gas) }\end{array}$ & PGSS \\
\hline 0.14 & 0.23 & Single phase & D-RESS \\
\hline
\end{tabular}
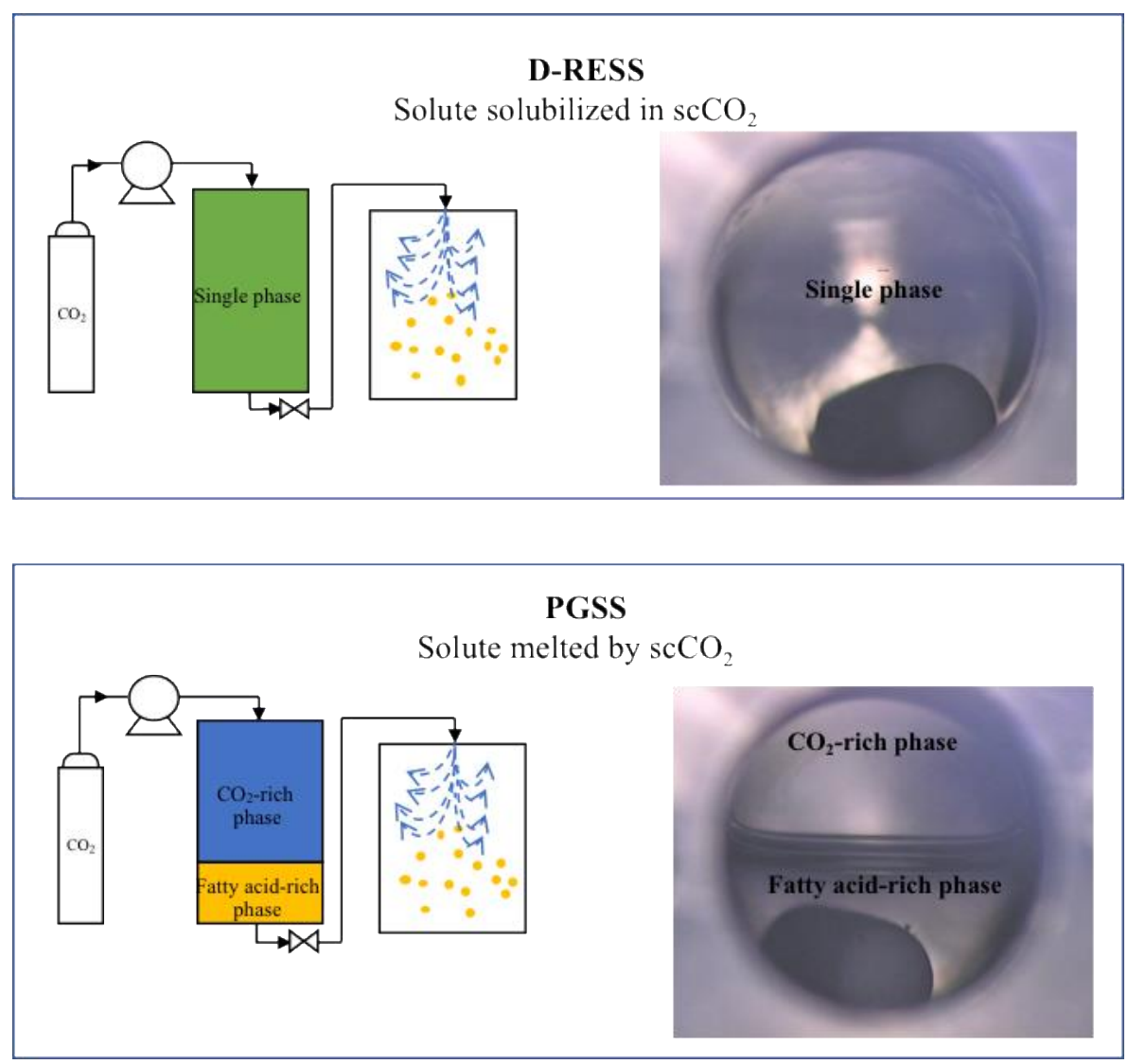

Figure 5. Schematic representation of PGSS and D-RESS with inset pictures of the high-pressure view cell.

In super-saturated conditions of fatty acids in $\mathrm{scCO}_{2}$, the autoclave is composed by a diphasic mixture with a liquid phase of melted fatty acid blends saturated with $\mathrm{CO}_{2}$ and a gas phase composed of $\mathrm{CO}_{2}$ saturated with fatty acids (Figure 5). These observations confirm the co-existence of two phases (i.e., liquid (fatty acid-rich phase) gas $\left(\mathrm{CO}_{2}\right.$-rich phase)) in the PGSS configuration and a single fluid phase in the D-RESS configuration. Depending on the process configuration (PGSS or D-RESS) different predefined amounts of LA and MA were introduced in the autoclave. In a PGSS configuration, the amount of each fatty acid was higher than its solubility in $\mathrm{scCO}_{2}$, while 
respecting a molar ratio between both fatty acids of 1:1 (i.e., LA content/LA solubility and MA content/MA solubility were 1.25 and 1.61, respectively). Thus, using PGSS configuration, gauzes present high loading rates, which results in a deposition of a thick layer of fatty acids on gauzes (Figure 6). Such high loading rates lead to a cytotoxicity similar to the latex, which is used as positive control for cell death (Figure 7). From these results, it is clear that even though PGSS process is suitable for loading the gauzes the results are not adequate for biomedical application as the cell viability is compromised.

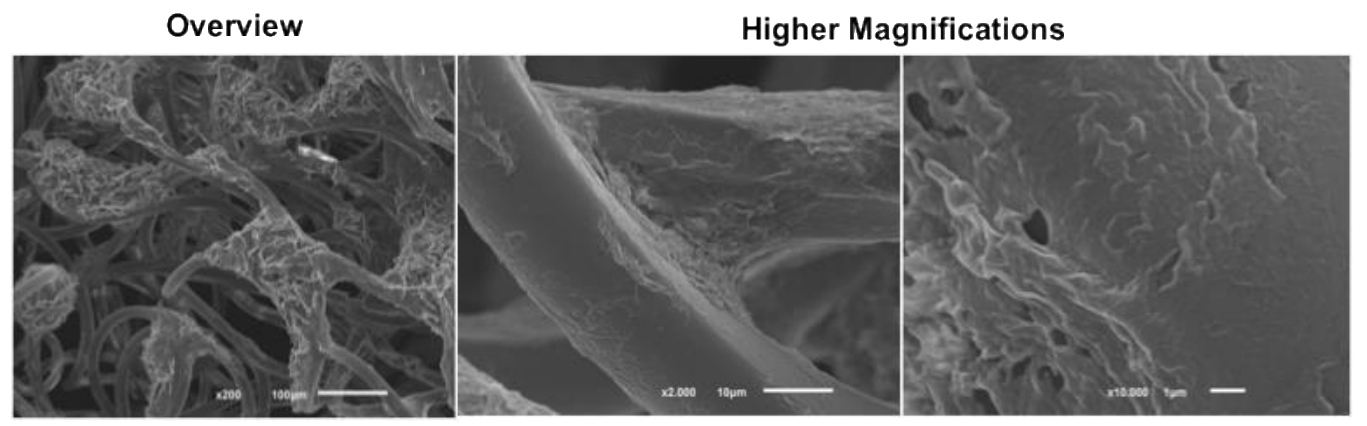

Figure 6. SEM micrographs of gauzes loaded with LA:MA by PGSS process.

A

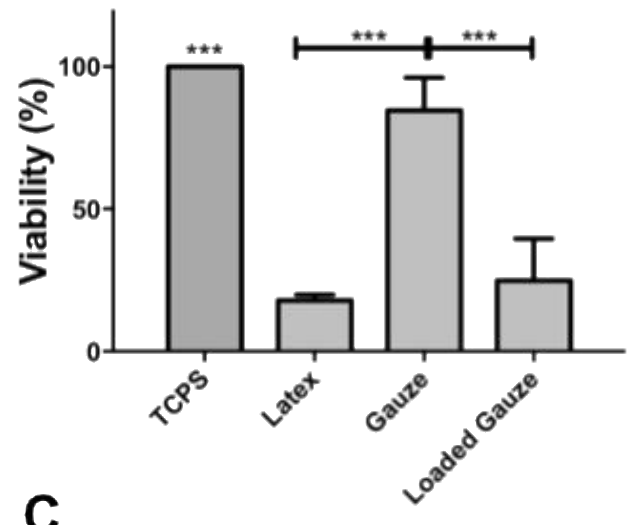

C

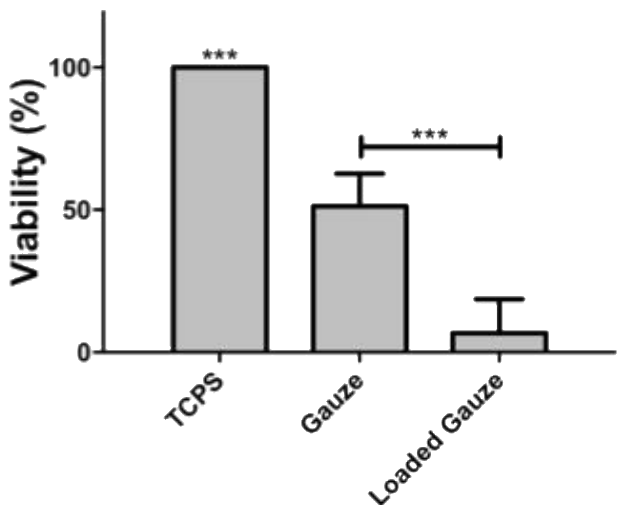

B

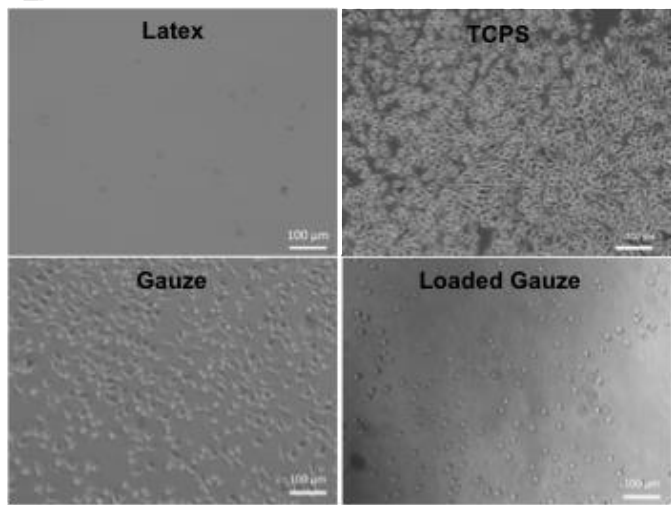

D

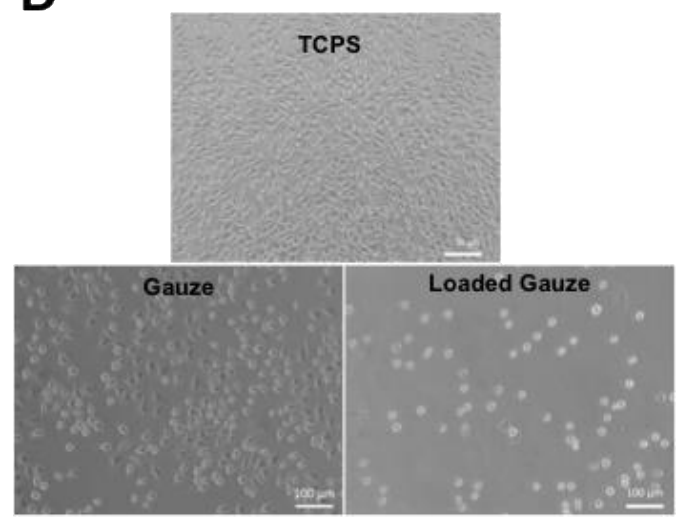

Figure 7. (A) Assessment of cell viability and (B) morphology upon contact with extracts of gauzes loaded with LA:MA eutectic blend by PGSS process and controls (Latex, TCPs). (C) Assessment 
of cell viability and (D) morphology upon direct contact with gauzes containing different amounts of fatty acids. Significance differences were found for $(* * *) p<0.001$.

Alternatively, when fatty acids are in under-saturated $\mathrm{scCO}_{2}$ conditions, a monophasic solution is obtained and the expansion process is similar to the RESS process. As the composition of the fluid phase changes with the projection cycles, i.e., fatty acids mass decreases while $\mathrm{scCO}_{2}$ is introduced in the autoclave to compensate the pressure decrease, the process was coined as a derived version of RESS process (D-RESS). DRESS configuration presents an easier alternative for the pulverization of a LA:MA:CO fluid phase, when compared with PGSS configuration, where a melted solution of fatty acids is saturated with $\mathrm{CO}_{2}$. The loading experiments on D-RESS configuration were performed using one projection cycle configuration and two gauzes $\left(1 \mathrm{~cm}^{2}\right.$ surface area each), where one gauze was placed in a central position (central position), while other was placed in a peripherical position (peripheral gauze) relatively to the jet cone of the atomization (Figure 8). The oil red staining, a specific staining for lipids and fatty acids, indicates a successful loading of gauzes, since a reddish colour was observed in both formulation, being the central gauze the one with increased colour intensity.[48, 49]

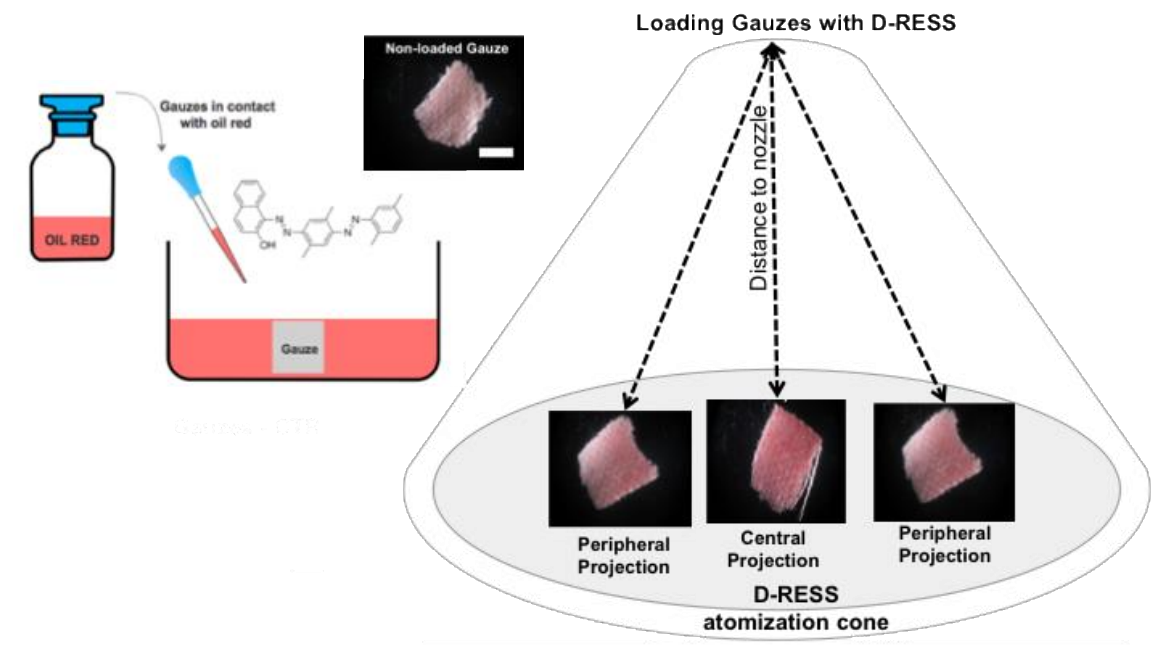

Figure 8. Oil red staining of gauzes with different amount of LA:MA eutectic blend. The scale bar is $0.5 \mathrm{~mm}$.

SEM observations were also performed for the gauzes loaded by D-RESS process and the results indicate a homogeneous repartition of fatty acids along gauze's surface (Figure 9). The amount of fatty acids however increased as the position of the gauze changes from the center to the periphery of the jet projection area, since the distance between the sample and the nozzle changes, which influences the loading process.[65, 
66]

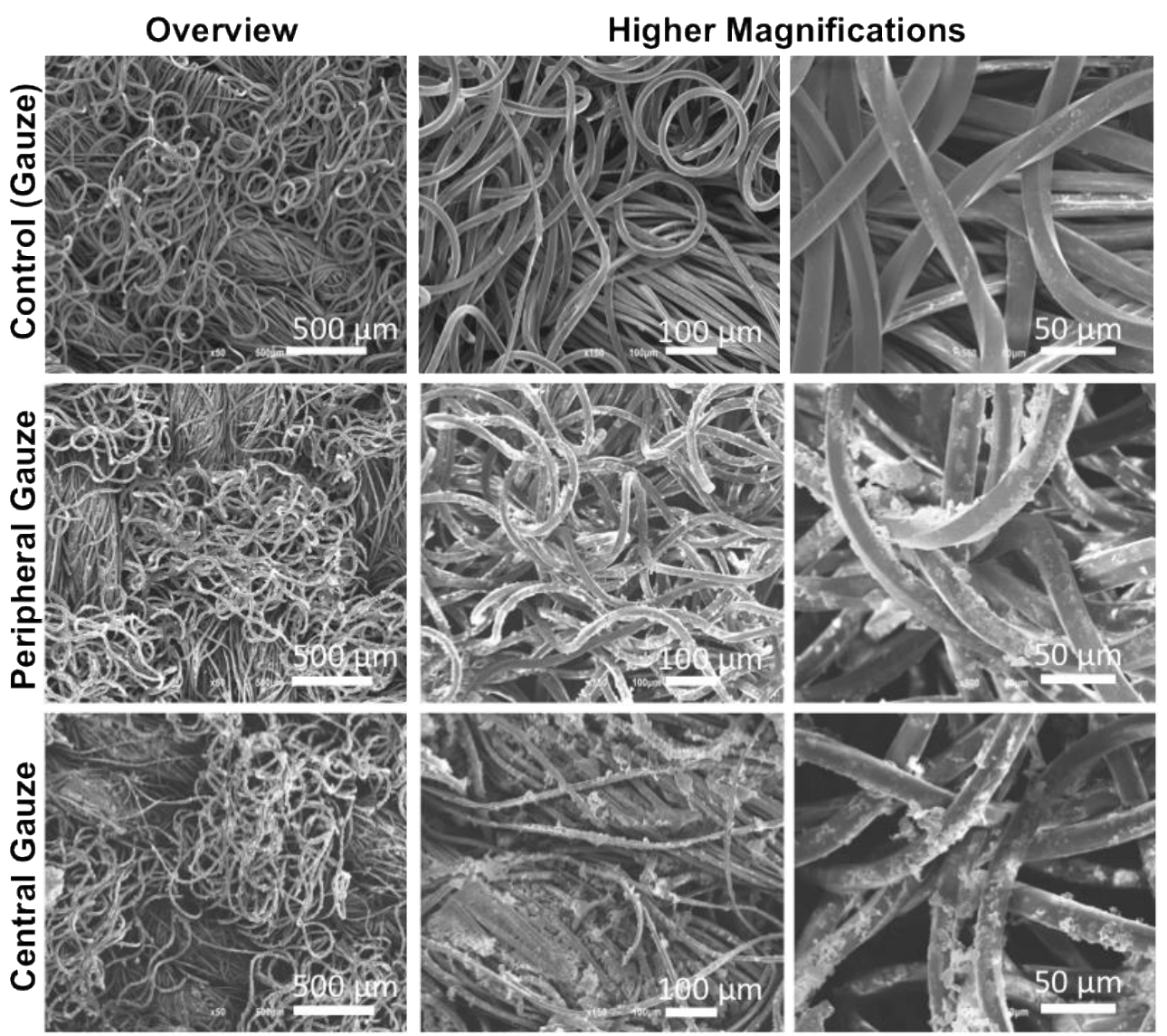

Figure 9: SEM micrographs of gauzes loaded with different amounts of LA:MA eutectic blend by D- RESS configuration.

In the D-RESS configuration, the amount of each fatty acid was lower than its solubility in $\mathrm{scCO}_{2}$, while respecting a molar ratio of 1:1 between both components (i.e., LA content/LA solubility and MA content/MA solubility were 0.14 and 0.23 , respectively). To confirm the data of fluid phase equilibria and the inexistence of phase separation, GC-MS analysis was carried out on the eutectic blend prepared and on the loaded gauzes (Table 5). The results indicate no phase separation occurs on the eutectic blend, since the molar ratio between LA:MA is kept upon D-RESS process. 
Table 5: Determination of the content of LA and MA in the eutectic blend and in gauzes (peripheral and central gauze).

\begin{tabular}{c|c|c}
\hline & LA (mg) & MA (mg) \\
\hline $\begin{array}{c}\text { Eutectic blend } \\
\text { (as prepared) }\end{array}$ & $6.78 \pm 3.8$ & $6.94 \pm 2.89$ \\
\hline Peripheral gauze & $0.11 \pm 0.02$ & $0.10 \pm 0.02$ \\
\hline Central gauze & $0.98 \pm 0.06$ & $1.16 \pm 0.06$ \\
\hline
\end{tabular}

The cytotoxic profile of the gauzes loaded with fatty acids was also evaluated against a L929 cell line, using a-DMEM extract method according to the ISO guidelines (Figure 4). To evaluate the biological performance, two approaches have also been considered. On the first approach, the cell viability did not significantly change upon increasing the amount of LA:MA eutectic blend increases (Figure 10A and 10B). These results are in accordance with results previously reported in the literature, since the viability varies in a dose-dependent manner being dependent on the nature of the raw materials, as well as from their interactions with the different functional groups present on the cells.[70-72] Alternately, when the loaded gauzes were in direct contact with the cell monolayer (Figure 10C and 10D), the values of cell viability were lower than the ones in indirect contact, which also occurred for the gauzes without fatty acids. These results can be explained by diffusion constraints (oxygen and nutrients) caused by the presence of gauzes on the top of cell monolayer. However, it should be pointed out that the attached cells remain viable and spread out along the surface. Upon increasing the amount of fatty acids (i.e., central gauze) the cell viability slightly decreases. 
A

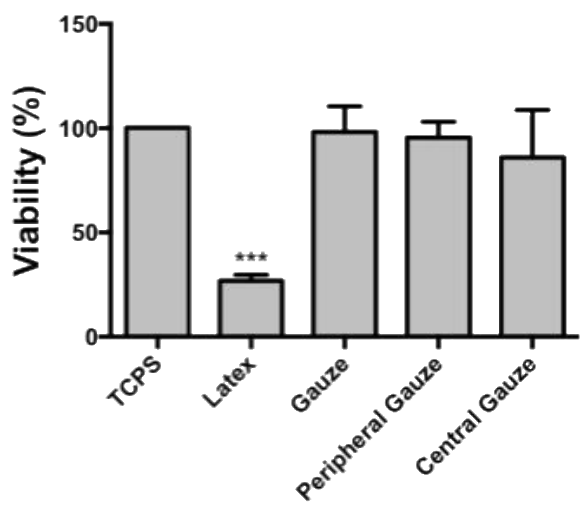

C

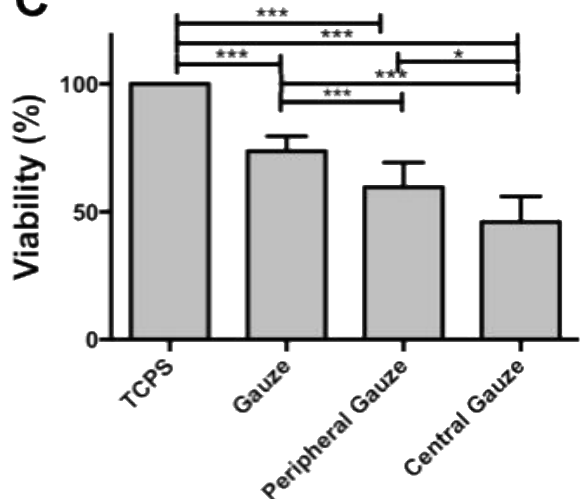

B

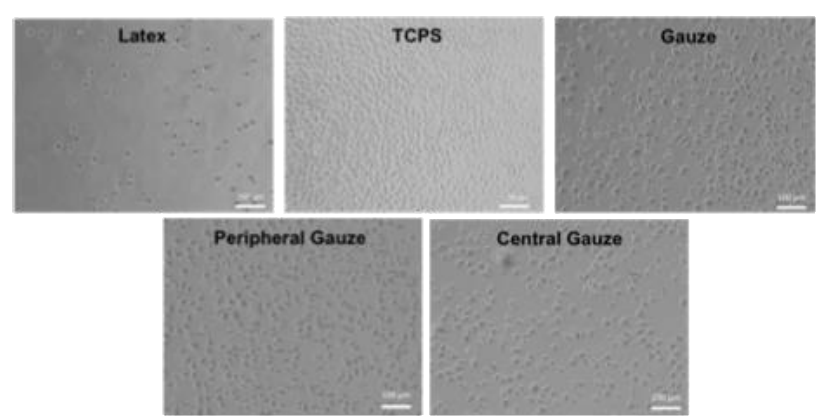

D

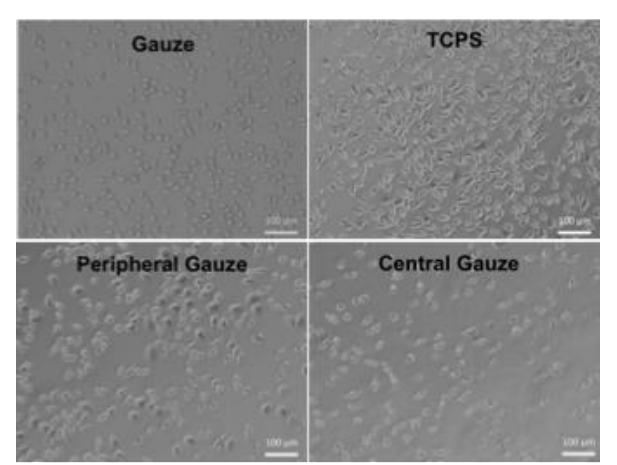

Figure 10. (A) Assessment of cell viability and (B) morphology upon contact with extracts of gauzes different amounts of LA:MA and controls (Latex, TCPS). (C) Assessment of cell viability and (D) morphology upon contact with gauzes containing different amounts of fatty acids. Significance differences were found for $(* * *) \mathrm{p}<0.001$ and $(*)$ $\mathrm{p}<0.05$.

The antibacterial activity of the gauzes loaded with fatty acids was then evaluated. The results indicate that the gauze without eutectic blend leads to a slightly decrease in CFUs due to the retention of bacteria in the gauzes' network. Upon loading with eutectic blend the gauze was more effective against S.aureus, which was consistent with the data obtained in eutectic blends. Comparing the central with the peripheral gauze no significant differences were found which indicates that an increase in eutectic blend loading does not impair the biologically activity towards S.aureus. This behaviour might be explained by the increase in the hydrophobicity as the amount of eutectic blend increases from the peripheral to the central position, which in turns decreases the solubility. Thereby, the solubility of fatty acids in solution reaches the saturation which may induce the formation of aggregates in aqueous solution, impairing their ability to interact with the cellular membrane of bacteria. 


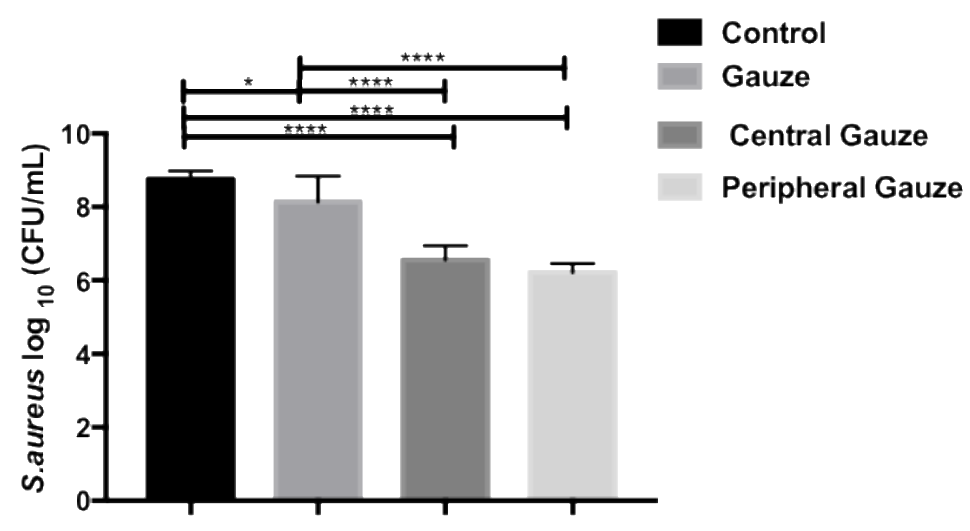

Figure 11. Colony counts of S.aureus upon overnight exposure to non-treated and treated gauzes (peripheral and central gauzes), as well as to control. Significance differences were found for $(* * *) p<0.001$ and $(*) p<0.05$.

To further confirm such effects, the morphology of the developed gauzes was also evaluated by SEM- see micrographs Figure 12. The results reveal that gauzes without treatment did not prevent bacteria colonization and the morphology of the bacteria remains similar to the positive control, where the bacteria are round and appeared as chains or clusters of cocci. Upon loading with eutectic blend, the gauzes present few aggregations of bacteria and induce changes on their dimensions and/or shape. Thus, the loss shape and irregularities in the cell membrane might be attributed to an increase in the membrane permeability due to the surfactant action of fatty acids which leads to disruption of cell membrane and loss of vital intracellular components, as previously reported for fatty acids.[44, 73] Comparing the morphology of S.aureus in peripheral and central gauzes, a similar trend was observed in both formulations, which further corroborated previous results. Overall, the results suggest that the D-RESS configuration and the amount of fatty acid is suitable to load medical devices, as the gauzes loaded with eutectic blends have demonstrated to be biologically activity towards S.aureus. These advantages may boost the use of eutectic blends in antibacterial wound dressings as the treatment with fatty acids are well known to decrease the development of spontaneous resistance to bacteria strains.[10] 

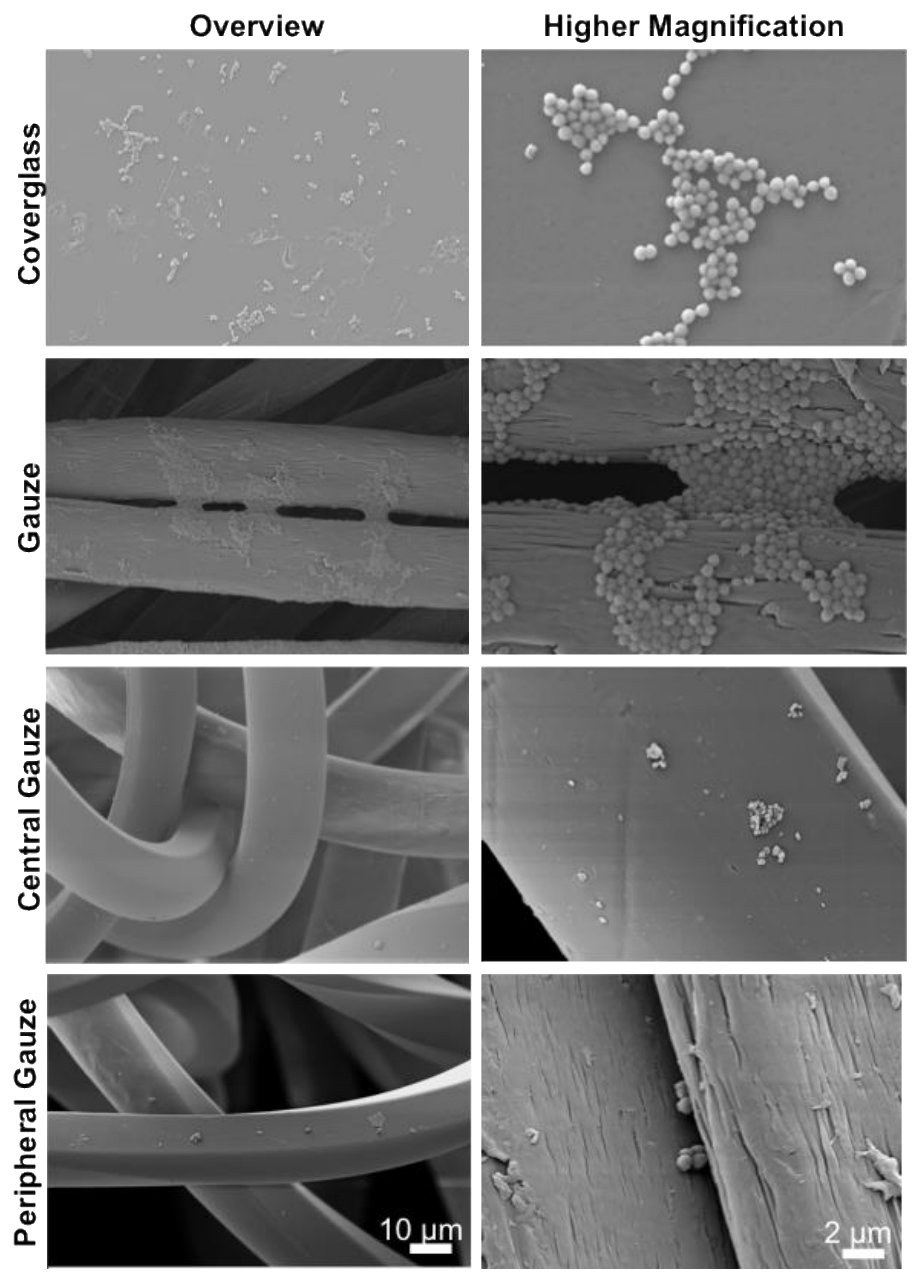

Figure 12. Morphology of S.aureus on the control (coverglass), gauze non-treated, central gauze and peripheral gauze. Scale bar represents $10 \mu \mathrm{m}$ and $2 \mu \mathrm{m}$ in lower and higher magnification images, respectively.

\section{CONCLUSION}

As efforts are ongoing to identify alternatives to antimicrobial treatments, in this work a new flexible process was developed to load medical devices, such as commercial gauzes. A derived version of the RESS process allows the generation of a homogeneous dispersion of LA:MA eutectic blend throughout the gauze, when compared with PGSS process. The thermo-responsive property of the eutectic blend allows the storage of the gauzes at RT without losing their function which together with its antibacterial properties turn the eutectic blend a valuable alternative to other antibacterial agents. Using this methodology, homogeneous samples can be obtained without phase separation between the fatty acid eutectic blend and $\mathrm{scCO}_{2}$. In addition, the loaded amount of fatty acid eutectic blend is easily controlled and, thus, it is possible to finely tune the antibacterial properties and the cytotoxic effects of the eutectic blend. This valuable feature together with the versatility and flexibility of the overall process open up new perspectives on the 
use of such approach on medical devices where it is crucial to confer antibacterial properties. The data also suggest a good prospect for wider use of eutectic blends in medical and/or biotechnological field.

\section{ACKNOWLEDGMENTS}

This work received funding from Foundation for Science and Technology (FCT), through project PTDC/BBB- 490 EBB/1676/2014 - Des.Zyme and ERC-2016-CoG 725034 (ERC Consolidator Grant Des.solve). Authors would also acknowledge the financial support by the "Institute Carnot Star" (France) for the development of the highpressure experimental setup. J.M.S. would also like to acknowledge the financial support by the Portuguese Foundation for Science and Technology (FCT) through the postdoctoral grant with reference number SFRH/BPD/116779/2016.

\section{REFERENCES}

[1] P. Gallart-Sirvent, M. Martín, G. Villorbina, M. Balcells, A. Solé, C. Barrenche, L.F. Cabeza, R. Canela-Garayoa, Fatty acid eutectic mixtures and derivatives from non-edible animal fat as phase change materials, RSC Advances 7(39) (2017) 24133-24139.

[2] E. Alptekin, M. Canakci, H. Sanli, Biodiesel production from vegetable oil and waste animal fats in a pilot plant, Waste Management 34(11) (2014) 2146-2154.

[3] B. Ouattara, R.E. Simard, R.A. Holley, G.J.-P. Piette, A. Bégin, Antibacterial activity of selected fatty acids and essential oils against six meat spoilage organisms, International journal of food microbiology 37(2) (1997) 155-162.

[4] G.J. Maximo, N.D. Carareto, M.C. Costa, A.O. dos Santos, L.P. Cardoso, M.A. Krähenbühl, A.J. Meirelles, On the solid-liquid equilibrium of binary mixtures of fatty alcohols and fatty acids, Fluid Phase Equilibria 366 (2014) 88-98.

[5] K. Tamura, T. Kasuga, T. Nakagawa, Phase behavior and solid-liquid equilibria of aliphatic and aromatic carboxylic acid mixtures, Fluid Phase Equilibria 420 (2016) 24-29. [6] M.C. Costa, L.A. Boros, M.P. Rolemberg, M.A. Krahenbuhl, A.J. Meirelles, Solid-liquid equilibrium of saturated fatty acids+ triacylglycerols, Journal of Chemical \& Engineering Data 55(2) (2010) 974-977.

[7] J.-H. Lee, Y.-W. Jo, Antimicrobial Effect of a Lauric Acid on Streptococcus Mutans Biofilm, (2016).

[8] M. Shilling, L. Matt, E. Rubin, M.P. Visitacion, N.A. Haller, S.F. Grey, C.J. Woolverton, Antimicrobial effects of virgin coconut oil and its medium-chain fatty acids on Clostridium difficile, Journal of medicinal food 16(12) (2013) 1079-1085.

[9] A. Ahmad, A. Ahmad, H. Varshney, A. Rauf, M. Rehan, N. Subbarao, A.U. Khan, Designing and synthesis of novel antimicrobial heterocyclic analogs of fatty acids, European journal of medicinal chemistry 70 (2013) 887-900.

[10] T. Nakatsuji, Kao, M. C., Fang, J. Y., Zouboulis, C. C., Zhang, L., Gallo, R. L., Huang, C. M., Antimicrobial property of lauric acid against Propionibacterium acnes: its 
therapeutic potential for inflammatory acne vulgaris, Journal of investigative dermatology 10(129) (2009) 2480-2488.

[11] O. Bystrenko, V. Kartuzov, Contact melting and the structure of binary eutectic near the eutectic point, Journal of Alloys and Compounds 617 (2014) 124-128.

[12] A. Sarı, Eutectic mixtures of some fatty acids for low temperature solar heating applications: thermal properties and thermal reliability, Applied Thermal Engineering 25(14) (2005) 2100-2107.

[13] A.P. Abbott, G. Capper, S. Gray, Design of improved deep eutectic solvents using hole theory, Chemphyschem: a European journal of chemical physics and physical chemistry 7(4) (2006) 803-806.

[14] P. Liu, J.-W. Hao, L.-P. Mo, Z.-H. Zhang, Recent advances in the application of deep eutectic solvents as sustainable media as well as catalysts in organic reactions, RSC Advances 5(60) (2015) 48675-48704.

[15] E.L. Smith, A.P. Abbott, K.S. Ryder, Deep eutectic solvents (DESs) and their applications, Chemical reviews 114(21) (2014) 11060-11082.

[16] D.V. Wagle, H. Zhao, G.A. Baker, Deep eutectic solvents: sustainable media for nanoscale and functional materials, Accounts of chemical research 47(8) (2014) 22992308.

[17] Y.P. Mbous, M. Hayyan, A. Hayyan, W.F. Wong, M.A. Hashim, C.Y. Looi, Applications of deep eutectic solvents in biotechnology and bioengineering-promises and challenges, Biotechnology advances 35(2) (2017) 105-134.

[18] A. Paiva, R. Craveiro, I. Aroso, M. Martins, R.L. Reis, A.R.C. Duarte, Natural deep eutectic solvents-solvents for the 21st century, ACS Sustainable Chemistry \& Engineering 2(5) (2014) 1063-1071.

[19] Y. Yuan, N. Zhang, W. Tao, X. Cao, Y. He, Fatty acids as phase change materials: a review, Renewable and Sustainable Energy Reviews 29 (2014) 482-498.

[20] B. Tang, K.H. Row, Recent developments in deep eutectic solvents in chemical sciences, Monatshefte für Chemie-Chemical Monthly 144(10) (2013) 1427-1454.

[21] Q. Zhang, K.D.O. Vigier, S. Royer, F. Jerome, Deep eutectic solvents: syntheses, properties and applications, Chemical Society Reviews 41(21) (2012) 7108-7146.

[22] D.A. Alonso, A. Baeza, R. Chinchilla, G. Guillena, I.M. Pastor, D.J. Ramón, Deep eutectic solvents: the organic reaction medium of the century, European Journal of Organic Chemistry 2016(4) (2016) 612-632.

[23] M.C. Serrano, M.C. Gutiérrez, R. Jiménez, M.L. Ferrer, F. del Monte, Synthesis of novel lidocaine-releasing poly (diol-co-citrate) elastomers by using deep eutectic solvents, Chemical Communications 48(4) (2012) 579-581.

[24] I.M. Aroso, R. Craveiro, Â. Rocha, M. Dionísio, S. Barreiros, R.L. Reis, A. Paiva, A.R.C. Duarte, Design of controlled release systems for THEDES - therapeutic deep eutectic solvents, using supercritical fluid technology, International journal of pharmaceutics 492(1-2) (2015) 73-79.

[25] I.M. Aroso, J.C. Silva, F. Mano, A.S. Ferreira, M. Dionísio, I. Sá-Nogueira, S. Barreiros, R.L. Reis, A. Paiva, A.R.C. Duarte, Dissolution enhancement of active pharmaceutical ingredients by therapeutic deep eutectic systems, European Journal of Pharmaceutics and Biopharmaceutics 98 (2016) 57-66.

[26] F. Mano, M. Martins, I. Sá-Nogueira, S. Barreiros, J.P. Borges, R.L. Reis, A.R.C. Duarte, A. Paiva, Production of electrospun fast-dissolving drug delivery systems with 
therapeutic eutectic systems encapsulated in gelatin, AAPS PharmSciTech 18(7) (2017) 2579-2585.

[27] J.M. Silva, R.L. Reis, A. Paiva, A.R.C. Duarte, Design of functional therapeutic deep eutectic solvents based on choline chloride and ascorbic acid, ACS Sustainable Chemistry \& Engineering (2018).

[28] A.R.C. Duarte, A.S.D. Ferreira, S. Barreiros, E. Cabrita, R.L. Reis, A. Paiva, A comparison between pure active pharmaceutical ingredients and therapeutic deep eutectic solvents: Solubility and permeability studies, European Journal of Pharmaceutics and Biopharmaceutics 114 (2017) 296-304.

[29] H.G. Morrison, C.C. Sun, S. Neervannan, Characterization of thermal behavior of deep eutectic solvents and their potential as drug solubilization vehicles, International journal of pharmaceutics 378(1-2) (2009) 136-139.

[30] P.W. Stott, Williams, A.C., Barry, B.W., Transdermal delivery from eutectic systems: enhanced permeation of a model drug, ibuprofen, J. Control. Release 50((1-3)) (1998) 297-308.

[31] L. Wang, D. Meng, Fatty acid eutectic/polymethyl methacrylate composite as formstable phase change material for thermal energy storage, Applied Energy 87(8) (2010) 2660-2665.

[32] H. Ke, Phase diagrams, eutectic mass ratios and thermal energy storage properties of multiple fatty acid eutectics as novel solid-liquid phase change materials for storage and retrieval of thermal energy, Applied Thermal Engineering 113 (2017) 1319-1331.

[33] Y. Cai, Xu, X., Gao, C., Bian, T., Qiao, H., \& Wei, Q. , Structural morphology and thermal performance of composite phase change materials consisting of capric acid series fatty acid eutectics and electrospun polyamide6 nanofibers for thermal energy storage, Materials Letters 89 (2012) 43-46.

[34] X. Zong, Y. Cai, G. Sun, Y. Zhao, F. Huang, L. Song, Y. Hu, H. Fong, Q. Wei, Fabrication and characterization of electrospun $\mathrm{SiO} 2$ nanofibers absorbed with fatty acid eutectics for thermal energy storage/retrieval, Solar Energy Materials and Solar Cells 132 (2015) 183-190.

[35] H. Ke, Li, Y., Wang, J., Peng, B., Cai, Y., Wei, Q, Ag-coated polyurethane fibers membranes absorbed with quinary fatty acid eutectics solid-liquid phase change materials for storage and retrieval of thermal energy, Renewable Energy 99 (2016) 1-9

[36] P. Zhao, Q. Yue, H. He, B. Gao, Y. Wang, Q. Li, Study on phase diagram of fatty acids mixtures to determine eutectic temperatures and the corresponding mixing proportions, Applied Energy 115 (2014) 483-490.

[37] A. Martín, M.J. Cocero, Micronization processes with supercritical fluids: fundamentals and mechanisms, Advanced Drug Delivery Reviews 60(3) (2008) 339-350. [38] O. Nuchuchua, M.R. Nejadnik, S.C. Goulooze, N.J. Lješković, H.A. Every, W. Jiskoot, Characterization of drug delivery particles produced by supercritical carbon dioxide technologies, The Journal of Supercritical Fluids (2017).

[39] J. Hao, M.J. Whitaker, B. Wong, G. Serhatkulu, K.M. Shakesheff, S.M. Howdle, Plasticization and spraying of poly (DL-lactic acid) using supercritical carbon dioxide: control of particle size, Journal of pharmaceutical sciences 93(4) (2004) 1083-1090.

[40] D.L. Tomasko, H. Li, D. Liu, X. Han, M.J. Wingert, L.J. Lee, K.W. Koelling, A review of CO2 applications in the processing of polymers, Industrial \& Engineering Chemistry Research 42(25) (2003) 6431-6456. 
[41] V.S.S. Gonçalves, A.A. Matias, S. Rodríguez-Rojo, I.D. Nogueira, C.M.M. Duarte, Supercritical fluid precipitation of ketoprofen in novel structured lipid carriers for enhanced mucosal delivery-a comparison with solid lipid particles, International journal of pharmaceutics 495(1) (2015) 302-311.

[42] A. São Pedro, S. Dalla Villa, P. Caliceti, S.A.B.V. de Melo, E.C. Albuquerque, A. Bertucco, S. Salmaso, Curcumin-loaded solid lipid particles by PGSS technology, The Journal of Supercritical Fluids 107 (2016) 534-541.

[43] D.W. Matson, J.L. Fulton, R.C. Petersen, R.D. Smith, Rapid expansion of supercritical fluid solutions: solute formation of powders, thin films, and fibers, Industrial \& Engineering Chemistry Research 26(11) (1987) 2298-2306.

[44] J.J. Kabara, D.M. Swieczkowski, A.J. Conley, J.P. Truant, Fatty acids and derivatives as antimicrobial agents, Antimicrobial agents and chemotherapy 2(1) (1972) 23-28.

[45] T. Kitahara, N. Koyama, J. Matsuda, Y. Aoyama, Y. Hirakata, S. Kamihira, S. Kohno, M. Nakashima, H. Sasaki, Antimicrobial activity of saturated fatty acids and fatty amines against methicillin-resistant Staphylococcus aureus, Biological and Pharmaceutical Bulletin 27(9) (2004) 1321-1326.

[46] B. Ouattara, R.E. Simard, R.A. Holley, G.J.-P. Piette, A. Bégin, Antibacterial activity of selected fatty acids and essential oils against six meat spoilage organisms, International journal of food microbiology 37(2-3) (1997) 155-162.

[47] C. Crampon, G. Charbit, E. Neau, High-pressure apparatus for phase equilibria studies: solubility of fatty acid esters in supercritical CO 2, The Journal of supercritical fluids 16(1) (1999) 11-20.

[48] J. Ramirez-Zacarias, F. Castro-Munozledo, W. Kuri-Harcuch, Quantitation of adipose conversion and triglycerides by staining intracytoplasmic lipids with Oil red $O$, Histochemistry and Cell Biology 97(6) (1992) 493-497.

[49] R. Koopman, G. Schaart, M.K. Hesselink, Optimisation of oil red O staining permits combination with immunofluorescence and automated quantification of lipids, Histochemistry and cell biology 116(1) (2001) 63-68.

[50] E. Sertoglu, I. Kurt, S. Tapan, M. Uyanik, M.A. Serdar, H. Kayadibi, S. El-Fawaeir, Comparison of plasma and erythrocyte membrane fatty acid compositions in patients with end-stage renal disease and type 2 diabetes mellitus, Chemistry and Physics of Lipids 178 (2014) 11-17.

[51] Q.-F. Zhu, J.-W. Yan, Y. Gao, J.-W. Zhang, B.-F. Yuan, Y.-Q. Feng, Highly sensitive determination of fatty acid esters of hydroxyl fatty acids by liquid chromatography-mass spectrometry, Journal of Chromatography B 1061 (2017) 34-40.

[52] Y. Cai, H. Ke, L. Lin, X. Fei, Q. Wei, L. Song, Y. Hu, H. Fong, Preparation, morphology and thermal properties of electrospun fatty acid eutectics/polyethylene terephthalate form-stable phase change ultrafine composite fibers for thermal energy storage, Energy conversion and management 64 (2012) 245-255.

[53] H. Fauzi, H.S. Metselaar, T. Mahlia, M. Silakhori, H. Nur, Phase change material: optimizing the thermal properties and thermal conductivity of myristic acid/palmitic acid eutectic mixture with acid-based surfactants, Applied Thermal Engineering 60(1) (2013) 261-265.

[54] H. Ke, Z. Pang, B. Peng, J. Wang, Y. Cai, F. Huang, Q. Wei, Thermal energy storage and retrieval properties of form-stable phase change nanofibrous mats based on ternary fatty acid eutectics/polyacrylonitrile composite by magnetron sputtering of silver, Journal of Thermal Analysis and Calorimetry 123(2) (2016) 1293-1307. 
[55] C. Alkan, A. Sari, Fatty acid/poly (methyl methacrylate)(PMMA) blends as formstable phase change materials for latent heat thermal energy storage, Solar energy 82(2) (2008) 118-124.

[56] G. Diarce, I. Gandarias, A. Campos-Celador, A. García-Romero, U. Griesser, Eutectic mixtures of sugar alcohols for thermal energy storage in the 50-90 C temperature range, Solar Energy Materials and Solar Cells 134 (2015) 215-226.

[57] K. Kant, A. Shukla, A. Sharma, Ternary mixture of fatty acids as phase change materials for thermal energy storage applications, Energy Reports 2 (2016) 274-279.

[58] S. Gisladottir, T. Loftsson, E. Stefansson, Diffusion characteristics of vitreous humour and saline solution follow the Stokes Einstein equation, Graefe's archive for clinical and experimental ophthalmology 247(12) (2009) 1677-1684.

[59] S. Gisladottir, T. Loftsson, E. Stefansson, Diffusion in the vitreous cavity is related to the viscosity of the medium according to the Stokes Einstein equation, Investigative Ophthalmology \& Visual Science 48(13) (2007) 5783-5783.

[60] K. Glinel, Thebault, P., Humblot, V., Pradier, C. M., Jouenne, T. , Antibacterial surfaces developed from bio-inspired approaches, Acta biomaterialia 8(5) (2012) 16701684.

[61] S. García-Argüelles, Serrano, M. C., Gutiérrez, M. C., Ferrer, M. L., Yuste, L., Rojo, F., del Monte, F. , Deep eutectic solvent-assisted synthesis of biodegradable polyesters with antibacterial properties. Langmuir, 29(30), , Langmuir 29(30) (2013) 9525-9534.

[62] F. Gomes, Martins, N., Barros, L., Rodrigues, M. E., Oliveira, M. B. P., Henriques, M.,Ferreira, I. C., Plant phenolic extracts as an effective strategy to control Staphylococcus aureus, the dairy industry pathogen, Industrial Crops and Products 12 (2018) 515-520.

[63] L. McGaw, A. Jäger, J. Van Staden, P. Houghton, Antibacterial effects of fatty acids and related compounds from plants, South African journal of botany 68(4) (2002) 417423.

[64] A.P. Desbois, V.J. Smith, Antibacterial free fatty acids: activities, mechanisms of action and biotechnological potential, Applied microbiology and biotechnology 85(6) (2010) 1629-1642.

[65] X. Li, M. Hou, B. Han, X. Wang, L. Zou, Solubility of CO2 in a choline chloride+ urea eutectic mixture, Journal of Chemical \& Engineering Data 53(2) (2008) 548-550.

[66] F.P. Lucien, N.R. Foster, Solubilities of solid mixtures in supercritical carbon dioxide: a review, The Journal of Supercritical Fluids 17(2) (2000) 111-134.

[67] C. Garlapati, G. Madras, Solubilities of dodecanoic and tetradecanoic acids in supercritical CO2 with and without entrainers, Journal of Chemical \& Engineering Data 53(11) (2008) 2637-2641.

[68] Y. Iwai, T. Fukuda, Y. Koga, Y. Arai, Solubilities of myristic acid, palmitic acid, and cetyl alcohol in supercritical carbon dioxide at 35. degree. C, Journal of Chemical and Engineering Data 36(4) (1991) 430-432.

[69] P. Maheshwari, Z.L. Nikolov, T.M. White, R. Hartel, Solubility of fatty acids in supercritical carbon dioxide, Journal of the American Oil Chemists' Society 69(11) (1992) 1069-1076.

[70] M. Hayyan, Y.P. Mbous, C.Y. Looi, W.F. Wong, A. Hayyan, Z. Salleh, O. Mohd-Ali, Natural deep eutectic solvents: cytotoxic profile, SpringerPlus 5(1) (2016) 913. 
[71] M. Hayyan, M.A. Hashim, A. Hayyan, M.A. Al-Saadi, I.M. AlNashef, M.E. Mirghani, O.K. Saheed, Are deep eutectic solvents benign or toxic?, Chemosphere 90(7) (2013) 2193-2195.

[72] M. Hayyan, C.Y. Looi, A. Hayyan, W.F. Wong, M.A. Hashim, In vitro and in vivo toxicity profiling of ammonium-based deep eutectic solvents, PloS one 10(2) (2015) e0117934.

[73] C.J. Zheng, Yoo, J. S., Lee, T. G., Cho, H. Y., Kim, Y. H., Kim, W. G., Fatty acid synthesis is a target for antibacterial activity of unsaturated fatty acids, FEBS letters 23(597) (2005) 5157-5162. 